\title{
Pitting Corrosion of Aluminum in Sodium Chloride Solution and Analyses of Surface Films
}

\author{
Eiichi Sato, Masahisa Sato and Ikuo Uchiyama \\ Department of Industrial Chemistry, Faculty of Engineering, \\ Utsunomiya University*
}

\begin{abstract}
The anodic polarization behavior and time dependence of anodic current of $99.99 \%$ aluminum in $0.5 \mathrm{~N} \mathrm{NaCl}$ solution ( $\mathrm{pH} \mathrm{4}, 6,8.5,10$ and 12) were examined potentiostatially. The surface structure and the composition of corrosion product films formed on the surface were also observed by a scanning electron microscope, $\mathrm{X}$-ray microanalyzer and energy dispersion type X-ray spectrograph, and the pitting mechanism of pure aluminum was discussed. Pitting corrosion of pure aluminum in $0.5 \mathrm{~N} \mathrm{NaCl}$ at $\mathrm{pH} 8.5$ seemed to be caused by $\mathrm{Cl}^{-}$which enters through cracks at the interface between the surface film and a rhombic corrosion product formed at less noble potentials than the pitting potential. This rhombic substance was observed only at $\mathrm{pH} 8.5$, and was not formed at $\mathrm{pH} 4,6$, and 10 in $0.5 \mathrm{~N} \mathrm{NaCl}$ solutions. In $0.5 \mathrm{~N} \mathrm{NaCl}$ solution at $\mathrm{pH} 12$, the pitting corrosion was affected by chemical dissolution, thus the pitting potential became rather noble. The limiting current observed in the anodic polarization curves in the solutions of $\mathrm{pH} 8.5,10$ and 12 seems to be controled by the diffusion of $\mathrm{OH}^{-}$. The potential at which pits are induced for pure aluminum in $0.5 \mathrm{~N} \mathrm{NaCl}$ was about $-0.743 \mathrm{~V}$ at $\mathrm{pH} 4,-0.757 \mathrm{~V}$ at $\mathrm{pH} 6,-0.760 \mathrm{~V}$ at $\mathrm{pH} 8.5$, and $-0.710 \mathrm{~V}$ at $\mathrm{pH} 10$. The main components of the rhombic corrosion product were ascertained as aluminum, iron, and silicon.
\end{abstract}

\section{Introduction}

Because of a number of complex factors involved, it has been difficult to analyze the mechanism in pitting corrosion of aluminum in sea water. To elucidate the initiation and growth of the corrosion, therefore, the anodic polarization characteristics of aluminum in $0.5 \mathrm{~N}$ sodium chloride solutions were studied. This paper describes the current-potential and current-time curves measured by potentiostatic techniques and the surface microstructure of aluminum after electrolysis.

\section{Experimental Procedure}

High purity aluminum plates $(99.99 \%$ ) were used as specimens. The size of the specimens was $1 \times 1 \mathrm{~cm}$ and $1 \mathrm{~mm}$ in thickness. The specimens were first chemically polished using $10 \%$ sodium hydroxide solution at $70^{\circ} \mathrm{C}$, and then $30 \%$ nitric acid solution. After the polishing, the specimens were thoroughly washed with distilled water. By this sequence of preparation, a homogeneous surface microstructure was obtained.

For adjusting $\mathrm{pH}$ of solutions, reagent grade hydrochloric acid and sodium hydroxide were used. The technique used to remove dissolved

\footnotetext{
* 2753, Ishiimachi, Utsunomiya 321-31, Japan
}

oxygen from electrolyte is described elsewhere. ${ }^{11}$ Corrosion potentials were measured with reference to a saturated calomel electrode.

Specimens were set in an electrolytic cell, and anodically polarized at a scanning rate of $8.3 \mathrm{mV}$ per minute. Furthermore, the potential was held constant for $60,60,30$ or 15 minutes at a rest potential, a more noble potential, a pitting incubation potential or the pitting potential. The specimens were then taken from the cell and washed thoroughly with distilled water. They were stored in a desiccator until used for the examination of surface microstructure. An oximechloroform extraction method (JIS K 0102) was used to analyze dissolved aluminum in the solution.

\section{Result and Discussion}

\subsection{Anodic Polarization Curves at Different pH Solutions}

The anodic current density increased as the applied potential became noble at $\mathrm{pH} 4$ and 6 (Fig. 1). Analysis for dissolved aluminum at both $\mathrm{pH}$ levels indicates that the increase of the anodic current density is caused by the following reaction through amorphous film formed at rest potentials:

$$
\mathrm{Al} \longrightarrow \mathrm{Al}^{3+}+3 \mathrm{e}
$$

A limiting current appears from $-1.2 \mathrm{~V}$ at $\mathrm{pH}$ 


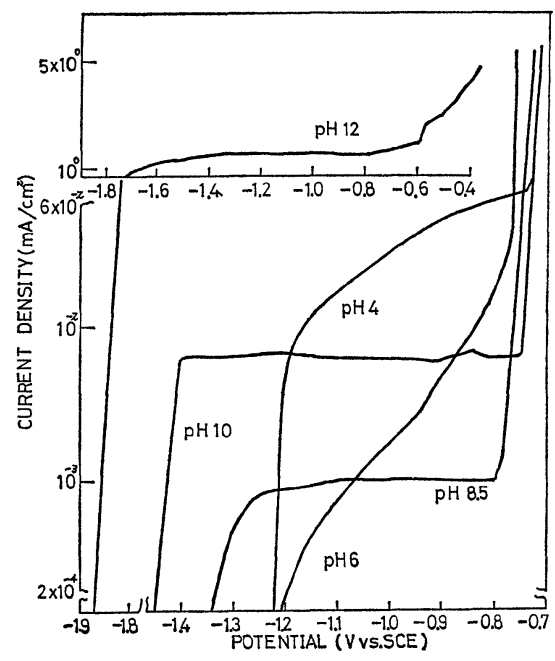

Fig. 1. Anodic polarization curves for $99.99 \%$ aluminum in deaerated $0.5 \mathrm{~N} \mathrm{NaCl}$ solution at various $\mathrm{pH}$ values.

8.5 , and from $-1.5 \mathrm{~V}$ at $\mathrm{pH} 10$ and 12 , as shown in Fig. 1. The values of the limiting current are of the same orders of magnitude for five different types of aluminum tested in solutions of various sodium chloride concentrations. Consequently, the anodic limiting current for aluminum is independent of the concentration of chloride and of the purity of aluminum. The purity of the aluminum tested was in the range from $99.21 \%$ to $99.99 \%$, with the iron content of $0.01-0.53 \%$ and the silicon content of $0.01-0.12 \%$. The concentration of sodium chloride was changed from $0.001 \mathrm{~N}$ to $2 \mathrm{~N}$, but the $\mathrm{pH}$ levels were the same as those in the previous experiments.

The current density due to the $\mathrm{OH}^{-}$diffusion may be calculated by Fick's equation, assuming the diffusion layer to be $0.05 \mathrm{~cm} .^{2}$

$$
I_{d}=\frac{n \cdot F \cdot D \cdot C}{\delta}
$$

where $I_{d}$ is the $\mathrm{OH}^{-}$diffusion current density $(\mathrm{mA} /$ $\mathrm{cm}^{2}$ ), $\delta$ thickness of diffusion layer, $n$ number of transferring electrons, $D$ diffusion coefficient for $\mathrm{OH}^{-}\left(5.23 \times 10^{-5} \mathrm{~cm}^{2} / \mathrm{sec}\right),{ }^{3)} C$ concentration of $\mathrm{OH}^{-}$in electrolyte $\left(\mathrm{mol} / \mathrm{cm}^{3}\right)$, and $F$ Faraday constant.

The values calculated for the limiting current density are $3 \times 10^{-4}, 1 \times 10^{-2}$ and $1 \mathrm{~mA} / \mathrm{cm}^{2}$ for $\mathrm{pH} 8.5, \mathrm{pH} 10$ and 12, respectively. These values agree well with the values obtained by experiments.

The limiting current densities at 0,30 and $40^{\circ} \mathrm{C}$ at $\mathrm{pH} 8.5$ were $2.3 \times 10^{-4}, 8.4 \times 10^{-4}$ and $9 \times 10^{-4}$ $\mathrm{mA} / \mathrm{cm}^{2}$, respectively. The apparent activation energy is then estimated to be about $6.4 \mathrm{kcal} / \mathrm{mol}$. At $\mathrm{pH} \mathrm{10,} \mathrm{the} \mathrm{limiting} \mathrm{current} \mathrm{densities} \mathrm{are} 2.3$ $\times 10^{-3}, 6.2 \times 10^{-3}$ and $1.2 \times 10^{-2} \mathrm{~mA} / \mathrm{cm}^{2}$, respectively, at the three different temperatures, giving the apparent activation energy to be $7.5 \mathrm{kcal} / \mathrm{mol}$. It can be concluded from these data that the limiting current densities at a $\mathrm{pH}$ range from 8.5 to 12 results from the diffusion of $\mathrm{OH}^{-}$ions.

\subsection{Current-time Curves under Potentiostatic Polarization}

In basic solutions, the diffusion of $\mathrm{OH}^{-}$seems to be the rate-determining process. However, theoretical analyses of the process are difficult if a vertical electrode is used to measure the anodic polarization curve at the stationary state, since natural convection of the fluid would disturb the linear diffusion of the ions. Therefore, the effect of the convection must be eliminated by measuring the current against time.

In an initial period of time, $\delta$ in the Fick's equation is written

$$
\delta=\sqrt{\pi \cdot D \cdot t} \quad(t=\text { time in sec })
$$

Then, the diffusion current density is expressed as

$$
\begin{gathered}
I_{d}=\frac{n \cdot F \cdot D \cdot C}{\sqrt{\pi \cdot D \cdot t}}=\frac{K \cdot C}{\sqrt{t}} \\
\left(K=\frac{n \cdot F \cdot D}{\sqrt{\pi \cdot D}}\right)
\end{gathered}
$$

$\log I_{d}=(-1 / 2) \log t+C^{\prime} \quad C^{\prime}=$ constant

If the applied potential is constant, the diffusion current density is a function of time. If the slope of $-1 / 2$ in the $\log I_{d}-\log t$ curve is satisfied, it could be postulated that the diffusion of $\mathrm{OH}^{-}$is the rate-determining process.

When the solution was agitated by purging pure nitrogen gas in the cell, the current density increased tenfold compared to that in stagnant solution. But the slope of $\log I_{d}-\log t$ curves did not satisfy $-1 / 2$.

Figure 2 shows $\log I-\log t$ curves under potentiostatic polarization at $-1.10,-0.90$ and $-0.75 \mathrm{~V}$ (pitting incubation potentials) and at $-0.70 \mathrm{~V}$ (pitting corrosion potential). The potential of the pitting corrosion induction corresponds to the potential at which the anodic current shows a sudden increase and decrease in the polarization curve. The pitting corrosion potential corresponds to the potential where the anodic current increases more quickly in the more noble potentials than does the potential of the pitting induction.

At $-1.10 \mathrm{~V}$, almost no current change was observed for 3-50 seconds, but between 50 and 


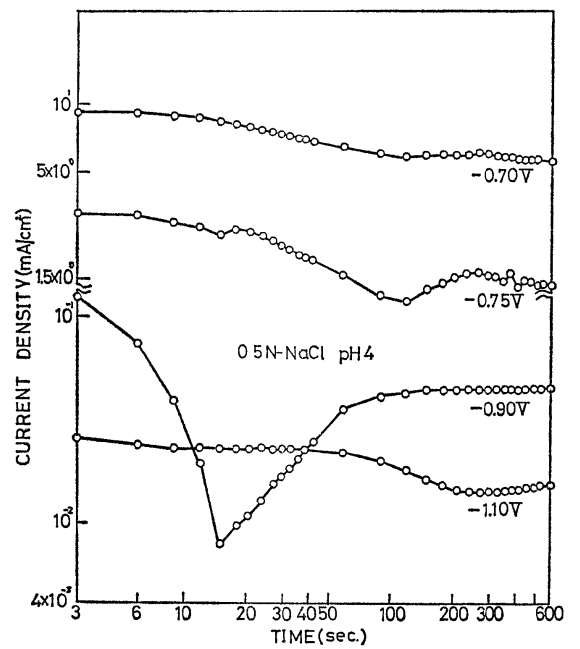

Fig. 2. Current-time curves for aluminum at constant potential at $\mathrm{pH} 4$.

200 seconds a slight linear reduction appeared. The fact can be considered, as pointed out by Franck, ${ }^{4)}$ as perhaps is suggesting the formation of an ion conductive film. Between 300 and 600 seconds, a slight increase of the anodic current was observed, which was due to the dissolution of the film formed.

At $-0.90 \mathrm{~V}$, it seemed that considerably rapid formation and dissolution were occurring. At the potential $-0.75 \mathrm{~V}$, where the pitting induction was anticipated, the formation of the ion conductive film occurred between 0 and 90 seconds, and after 100 seconds the anodic current increased with fluctuation.

At the potential $-0.70 \mathrm{~V}$, where pitting was occurring, a very large anodic current passed at the beginning and slightly decreased with the lapse of time. From the result of the experiment, the pitting reaction could be considered as was proceeding with a constant current density.

Figure 3 shows the relation between $\log I$ and $\log t$ of aluminum in a $0.5 \mathrm{~N} \mathrm{NaCl}$ solution with pH 6 under the constant potential polarization at $-1.10 \mathrm{~V},-0.90 \mathrm{~V}$ and $-0.72 \mathrm{~V}$ (pitting incuba. tion potential) as well as at $-0.72 \mathrm{~V}$ (pitting corrosion potential).

At $-1.10 \mathrm{~V}$, an ion conductive film was formed from the beginning of the electrolysis until 35 seconds, and the dissolution of the film seemed to be occurring after 150 seconds. At $-0.90 \mathrm{~V}$, the formation of an ion conductive film was observed during 0-200 seconds, and after 200 seconds the dissolution of the film occurred.

At $-0.72 \mathrm{~V}$, no film formation occurred until

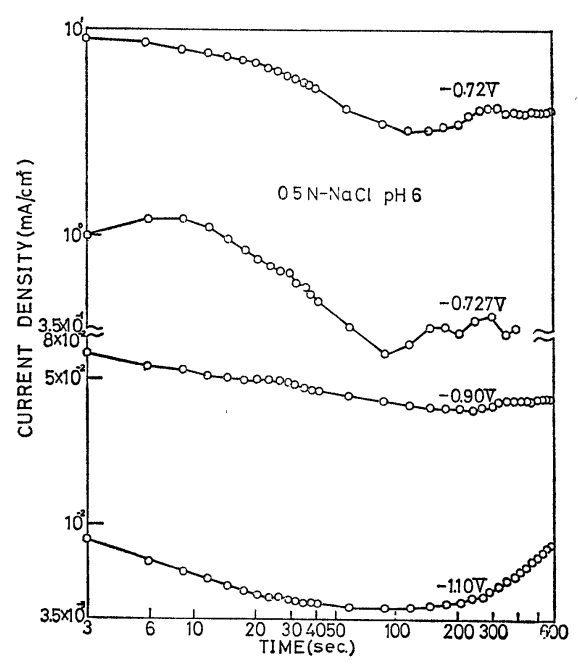

Fig. 3. Current-time curves for aluminum at constant potential at $\mathrm{pH} 6$.

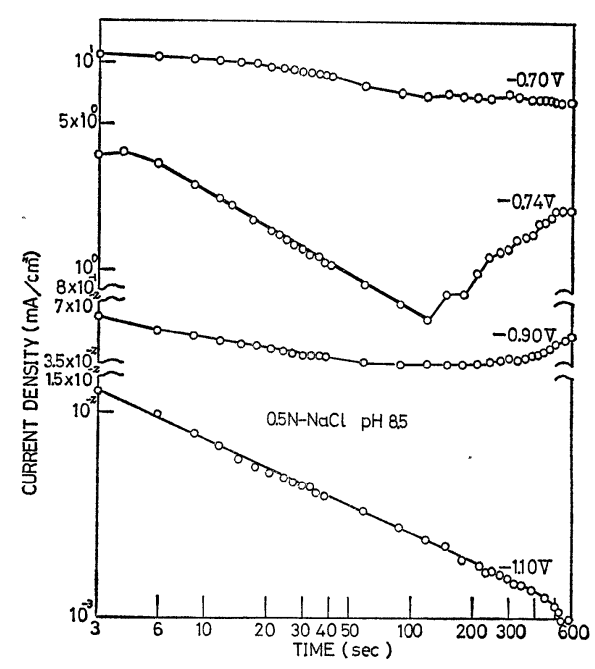

Fig. 4. Current-time curves for aluminum at constant potential at $\mathrm{pH} 8.5$.

10 seconds after the beginning of the electrolysis, and the formation of an ion conductive film began to occur during 10-90 seconds.

At the potential of $-1.10 \mathrm{~V}$, the slope of $\log I-$ $\log t$ curve is $-1 / 2$ between 3 and 459 seconds (Fig. 4). The anodic current density suddenly increased as a result of purging nitrogen gas in the cell. Based upon these observations, the diffusion of $\mathrm{OH}^{-}$seems to play a main role in the limiting current. At $-0.90 \mathrm{~V}$, the $\log I-\log t$ curve is linear between 3 and 30 seconds, but the gradient is not $-1 / 2$. Also, there is little change in the anodic current density between 3 and 300 seconds. Although the potential of $-0.90 \mathrm{~V}$ is located at a 


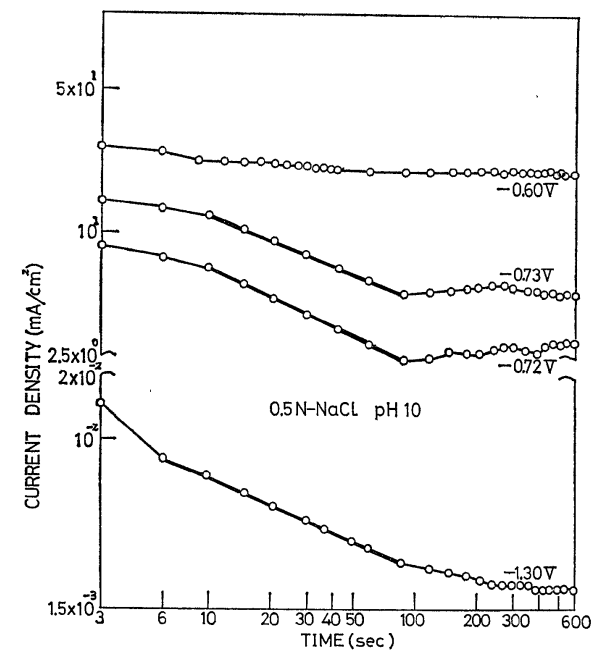

Fig. 5. Current-time curves for aluminum. at constant potential at $\mathrm{pH} 10$.

middle point between $-1.10 \mathrm{~V}$ and $-0.74 \mathrm{~V}$, the current-time curve is completely different from these at $-1.10 \mathrm{~V}$ and $-0.74 \mathrm{~V}$. The difference may have been caused by the formation of rhombic crystals on the aluminum substrate as observed by electron microscope.

At a pitting incubation potential of $-0.74 \mathrm{~V}$, the slope of $-1 / 2$ is observed between 6 and 100 seconds. The current density increases after agitation of the electrolyte. Therefore, the limiting current is possibly controlled by the diffusion of $\mathrm{OH}^{-}$. After 100 seconds the anodic current density oscillates, but tends to increase as a whole. At the pitting corrosion potential of $-0.70 \mathrm{~V}$, almost no change of the current ocurrs, although a detailed examination should reveal the formation of the electrolysis and the current due to pitting corrosion after 10 seconds.

At $\mathrm{pH} \mathrm{10,a} \mathrm{film} \mathrm{is} \mathrm{formed} \mathrm{on} \mathrm{aluminum} \mathrm{between}$ 3 and 10 seconds at $-1.30 \mathrm{~V}$ (Fig. 5). The slope of the curve is $-1 / 2$ between 10 and 90 seconds. With considering the shape of the curve, the electrochemical property of the specimens is assumed essentially the same as that in the solution of $\mathrm{pH} 8.5$ at $-1.10 \mathrm{~V}$. At the corrosion inducing potentials of -0.72 and $-0.75 \mathrm{~V}$, the slope of $\log I-\log t$ curve are the same. A film is formed between 3 and 10 seconds, and the slope is $-1 / 2$. However, two reactions, the dissolution of aluminum in solution and the formation of a surface film, take place simultaneously after 100 seconds. At $-0.60 \mathrm{~V}$, the formation of film is unlikely to occur. The $\log I-\log t$ curve is almost horizontal, which implies that the corrosion reaction

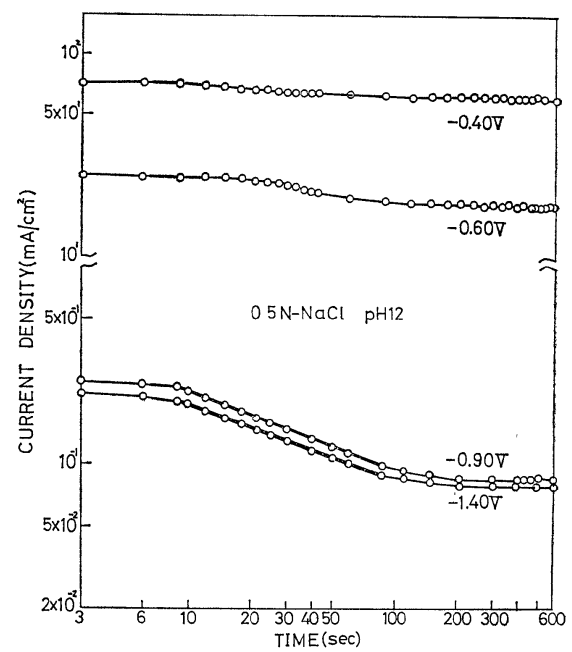

Fig. 6. Current-time curves for aluminum at constant potential at $\mathrm{pH} 12$.

starts at an early stage of electrolysis and continues at a constant current. The $\log I-\log t$ curve at $-0.40 \mathrm{~V}$ at $\mathrm{pH} 12$ is levelled off more than that at $-0.60 \mathrm{~V}$ at $\mathrm{pH} 10$, except in the early stages of electrolysis where a surface film must have been formed.

$\log I-\log t$ curves at pH 12 are shown in Fig. 6. The formation of a thick film does not occur because the curves at -0.40 and $-0.90 \mathrm{~V}$ are in the same shape, and a constant current density is observed between 3 and 10 seconds. Between 10 and 90 seconds, the curve is linear with a slope of $-1 / 2$. The anodic current may therefore be attributed to the diffusion of $\mathrm{OH}^{-}$. After 200 seconds, the dissolution of the film takes place. At $-0.60 \mathrm{~V}$, the following chemical reaction could be the rate determining process:

$$
\mathrm{Al}(\mathrm{OH})_{3}+\mathrm{OH}^{-} \longrightarrow \mathrm{Al}(\mathrm{OH})_{4}{ }^{-}
$$

This assumption is based upon the facts that the limiting current originates from the rate-determining process of chemical reactions. The limiting current in the vicinity of $-0.60 \mathrm{~V}$ is not affected by agitation, and the slope of $-1 / 2$ is not observed in the $\log I-\log t$ curves.

\subsection{Starting Potential of the Pitting Corrosion Induction}

The starting potential is the potential at which the current density suddenly increases and decreases in the polarization curve. The potentials are $-0.743,-0.757,-0.760$ and $-0.710 \mathrm{~V}$ for $\mathrm{pH} 4$, $6,8.5$ and 10 , respectively.

\subsection{Surface Structure of Aluminum}

The surface structures obtained in a $\mathrm{pH} 4$ solu- 


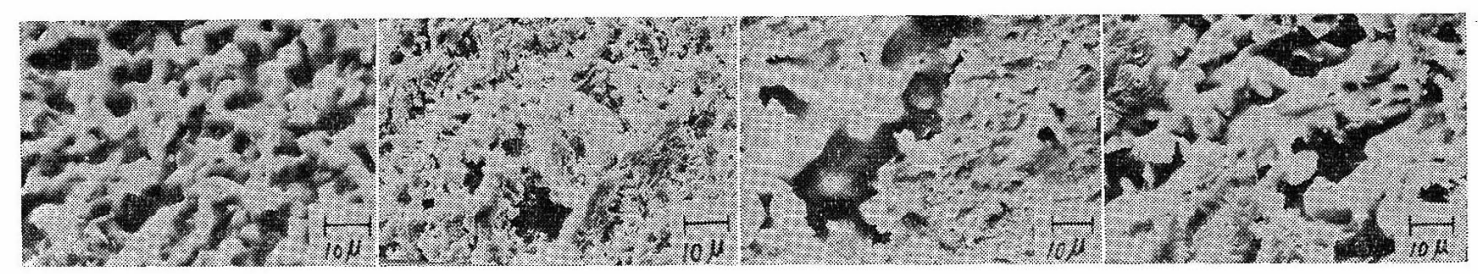

(a)

(b)

(c)

(d)

Fig. 7. Surface structure of polarized pure aluminum at $\mathrm{pH} 4$ in $0.5 \mathrm{~N} \mathrm{NaCl}$. (a) Potential $-1.10 \mathrm{~V}$, electrolysis $60 \mathrm{~min}$, (b) $-0.90 \mathrm{~V}, 60 \mathrm{~min}$, (c) $-0.75 \mathrm{~V}, 15 \mathrm{~min}$, (d) $-0.70 \mathrm{~V}$, $10 \mathrm{~min}$.

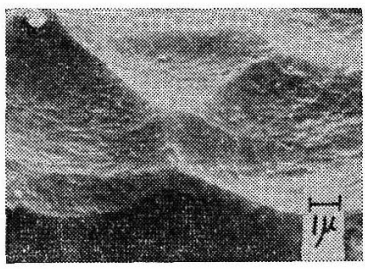

(a)

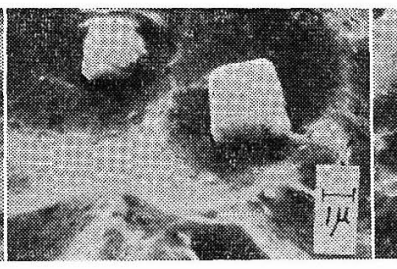

(b)

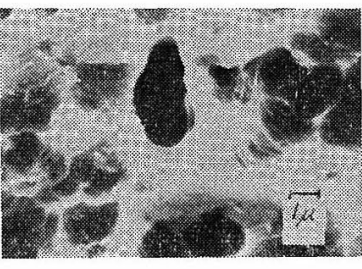

(c)

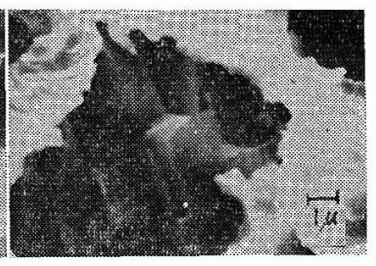

(d)

Fig. 8. Surface structure of polarized pure aluminum at pH 8.5 in $0.5 \mathrm{~N} \mathrm{NaCl}$. (a) Potential $-1.10 \mathrm{~V}$, electrolysis $60 \mathrm{~min},(\mathrm{~b})-0.90 \mathrm{~V}, 60 \mathrm{~min}$, (c) $-0.74 \mathrm{~V}, 30 \mathrm{~min}$, (d) $-0.72 \mathrm{~V}$, $15 \mathrm{~min}$.

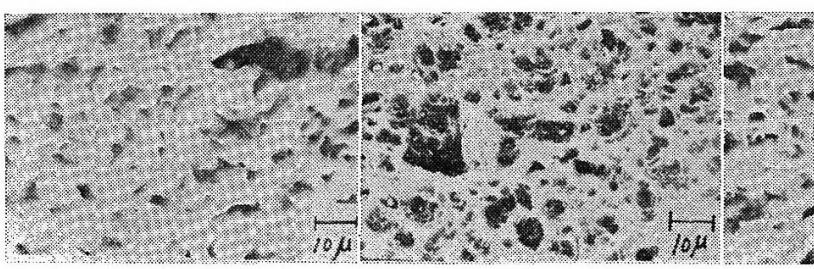

(a) (b)

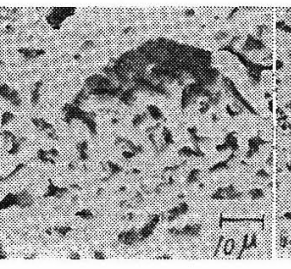

(c)

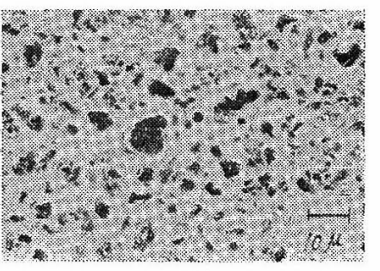

(d)

Fig. 9. Surface structure of polarized pure aluminum at $\mathrm{pH} 10$ in $0.5 \mathrm{~N} \mathrm{NaCl}$. (a) Potential $-1.30 \mathrm{~V}$, electrolysis $60 \mathrm{~min}$, (b) $-0.90 \mathrm{~V}, 60 \mathrm{~min}$, (c) $-0.72 \mathrm{~V}, 15 \mathrm{~min}$, (d) $-0.70 \mathrm{~V}$, $5 \mathrm{~min}$.

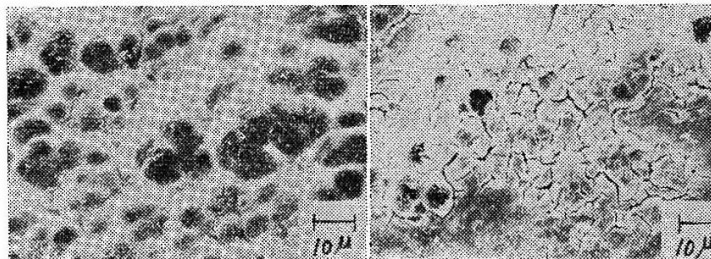

(a) (b)

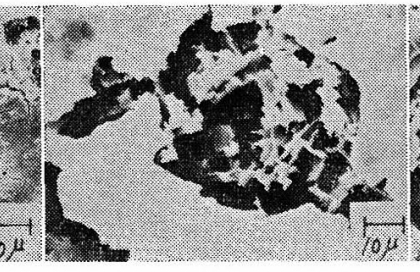

(c)

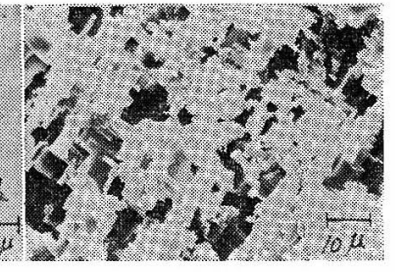

(d)

Fig. 10. Surface structure of polarized pure aluminum at $\mathrm{pH} 12$ in $0.5 \mathrm{~N} \mathrm{NaCl}$. (a) Potential $-1.40 \mathrm{~V}$, electrolysis $60 \mathrm{~min}$, (b) $-0.90 \mathrm{~V}, 60 \mathrm{~min}$, (c) $-0.60 \mathrm{~V}, 7 \mathrm{~min}$, (d) $-0.40 \mathrm{~V}$, 5 min.

tion are shown in Fig. 7. A waxy film is formed (Fig. 7-a). The film would be amorphous aluminum hydroxide. The fibrous surface structure resulting from the dissolution of the aluminum hydroxide is shown in Fig. 7-b. Fig. 7-c shows cracks and deep hollows, but the film is fairly smooth. Pitting corrosion has spread over the surface, so that the surface is very rough (Fig. 7-d).
The surface structures at $\mathrm{pH} 6$ are similar to those at $\mathrm{pH} 4$. At $\mathrm{pH} 8.5$, hemispherical hollows on the film are clearly seen (Fig. 8-a). Rhombic crystals grow inside the hollows (Fig. 8-b). The growth of the crystals is specific in neutral solutions. No such growth is observed in strong basic or acid solutions. The crystal seems to have grown from the inside of the film. Deep cracks 
surround the crystal. The diameter of the crystals is about 1 micron. Fig. $8-\mathrm{c}$ shows a corrosion pattern which would have been formed by dissolution of the rhombic crystals. Also, a wax-like film is seen. In Fig. 8-d, corrosion pits grow enough to destruct the surface film.

The surface inside the pits is not smooth, and corrosion pits develop along particular crystal facets. The surface structures at $\mathrm{pH} 10$ are shown in Fig. 9. An uneven and wax-like film with no pitting is observed (Fig. 9-a). The spongy surface formed by dissolution of the wax-like film, and the uneven wax-like film with cracks and pitting are shown in Fig. 9-b and Fig. 9-c. Corrosion is in progress, and spongy films are devel- oped (Fig. 9-d). At pH 12, hemispherical hollows developed (Fig. 10-a). Tiny cracks are seen, but the surface is still smooth (Fig. 10-b). Corrosion develops inside the film (Fig. 10-c). The development is in dendrite or mosic. Scale-like films are seen around the pits. The metal is highly corroded (Fig. 10-d). Mosic tissues inside the pit are seen.

3.5. Composition of the Films Formed on the Surface $^{53}$

Further, the composition of the substance formed on the surface were elucidated by use of a scanning electron microscope, an X-ray microanalyzer, and an energy dispersion type X-ray spectrograph (Fig. 11). The following points are

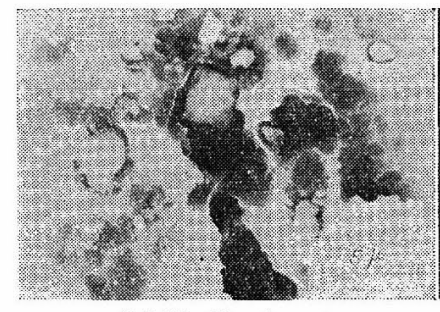

$-0.9 \mathrm{~V}, 60 \mathrm{~min}$ set

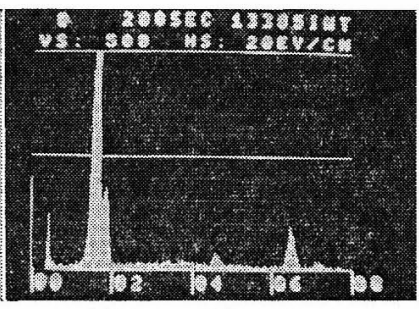

$\mathrm{AlSi} \quad \mathrm{Ti} \quad \mathrm{Fe}$

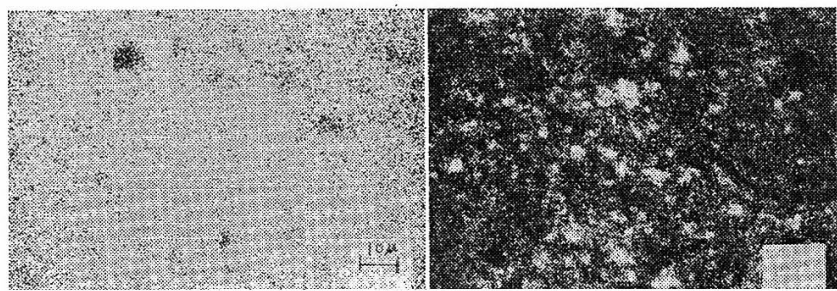

$\mathrm{Al}$

$\mathrm{Si}$

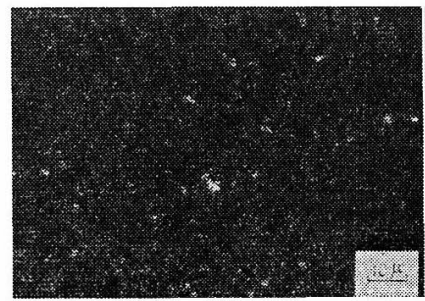

$\mathrm{Fe}$

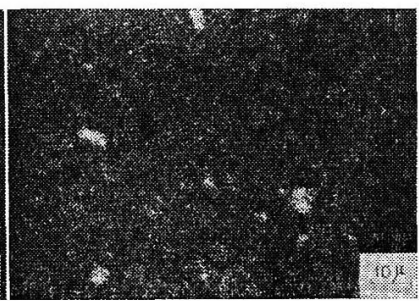

O

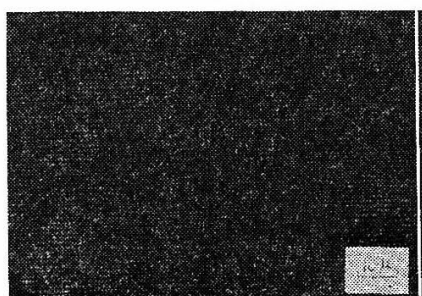

$\mathrm{Na}$

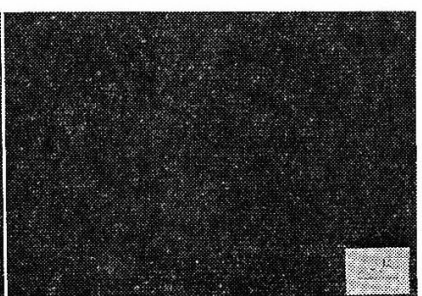

$\mathrm{Ti}$

Fig. 11. Observation and analyses of a corroded aluminum surface by scanning electron microscope, X-ray microanalyzer, and energy dispersion type X-ray spectrograph; pure aluminum in $0.5 \mathrm{~N} \mathrm{NaCl}$ of $\mathrm{pH} 8.5$. 
drawn from the results. The surface film formed by the anodic polarization could be considered as an aluminum hydroxide film on the basis of the existence of aluminum and oxygen. Also, it was ascertained that minute amounts of sodium and carbon coexisted in the surface film. On the other hand, it was also ascertained that no chloride ion was present in the surface film. From this fact, the chloride ion adsorption theory hitherto referred to become unable to be supported at least from a microscopic viewpoint. As described in details, the phenomena here can be considered perhaps in such a way that chloride ions diffuse in the cracks of the surface film to directly react with the metal aluminum to form corrosion products with very large solubility, which eventually dissolve away into the solution.

The reason of the coexistence of sodium and carbon may be considered as follows. The alkaline solution absorbes $\mathrm{CO}_{2}$ gas in air to form $\mathrm{NaCO}_{3}^{-}$,

$$
\mathrm{NaOH}+\mathrm{CO}_{2} \longrightarrow \mathrm{H}^{+}+\mathrm{NaCO}_{3}^{-}
$$

and the $\mathrm{NaCO}_{3}{ }^{-}$formed will react with the metal aluminum subjected to the anodic polarization, which may result in the existence of sodium, carbon, and oxygen on the electrode surface.

The main components of the rhombic substance were ascertained as aluminum, iron, and silicon on the basis of the energy distribution diagram of the electrons directly projected on the rhombic substance from the energy dispersion type X-ray spectrograph. Since the aluminum specimen is of high purity and shows uncertain crystal boundaries when electrically polished, it seems not conceivable that iron and silicon are concentrated in the crystal boundaries. However, when considered from the result of the diffraction with the energy dispersion type X-ray spectrograph (narrowing the beam width down to about 1 micron), it is without doubt that there are aggregates of such metal elements which are considered to act as cathodes in one hand and give strong influence to the structure of the surface film.

\section{Conclusion}

1) The corrosion of high purity aluminum in simulated sea water $(0.5 \mathrm{~N}$ sodium chloride solution at $\mathrm{pH} 8.5$ ) is initiated by the penetration of $\mathrm{Cl}^{-}$through cracks which are formed by the growth of rhombic crystals below the surface film. This occurs at more base potentials than pitting corrosion incubation potentials.

2) In alkaline solutions such as at $\mathrm{pH} 12$, the corrosion is also developed, but the pitting corrosion incubation potential region shifts in the more noble direction.

3) The anodic limiting current results from the diffusion of $\mathrm{OH}^{-}$at $\mathrm{pH} \mathrm{8.5,10}$ and 12 .

4) The pitting corrosion incubation potential region at $\mathrm{pH} 4$ is initiated from $-0.74 \mathrm{~V}$, at $\mathrm{pH} 6$ from $-0.75 \mathrm{~V}$, at $\mathrm{pH} 8.5$ from $-0.76 \mathrm{~V}$, and at $\mathrm{pH} 10$ from $-0.71 \mathrm{~V}$.

5) The main components of the rhombic corrosion product were ascertained as iron, aluminum, and silicon.

(Received January 21, 1975)

\section{References}

1) E. Sato, T. Tamura \& T. Okabe: J. Meta Finishing Soc. of Japan, 24, 139 (1973).

E. Sato, M. Oide \& T. Okabe: ibid., 24, 580 (1973).

2) "Denki Kagaku Binran," p. 248, Maruzen (1953).

3) S. Toshima: "Kiso Denki Kagaku," p. 262, Asakura Shoten (1972).

4) U. F. Franck: "Halbleiter Probleme," Bd. II, p. 216, Friedr. Vieweg \& Sohn Braunschweig (1955).

5) H. Hanemann \& A. Schrader: "Atlas Metallographicus," III, p. 109, Stahlelsen, M.B.H. (1952). 